\title{
UMA ANÁLISE DISCURSIVA DO SILÊNCIO NA PRISÃO
}

\section{LUCIANA IOST VINHAS ${ }^{1}$}

\author{
Centro de Letras e Comunicação, Universidade Federal de Pelotas \\ Rua Gomes Carneiro, 01 - 96010-610 - Pelotas - RS - Brasil \\ lucianavinhasegmail.com
}

\begin{abstract}
Resumo. Na teoria da Análise do Discurso, a resistência é constitutiva do processo de interpelação ideológica. O presente texto busca refletir sobre a resistência no interior da instituição penal ao analisar a fala de uma apenada entrevistada na Penitenciária Feminina Madre Pelletier. Essa análise também objetiva colocar em discussão o modo de funcionamento das prisões, conforme elaboração de Michel Foucault. As apenadas se calam frente à possibilidade de coerção das leis da Penitenciária, promovendo a resistência à dominação da instituição penal e instaurando outro modo de funcionamento da prisão a partir do interior das galerias, podendo ser retomado o enunciado pêcheuxtiano de que não há dominação sem resistência. $O$ dispositivo teórico-analítico da $A D$ permite que se chegue à relação citada através das marcas linguístico-prosódicas da materialização tanto da ideologia quanto de formas de resistência ao discurso dominante.
\end{abstract}

Palavras-chave: resistência; prisão; silêncio.

\begin{abstract}
In the French Discourse Analysis, resistance is known as an essential part of the process of ideological interpellation. The present study aims to think about resistance in the interior of the penal institution through the analysis of the speech of an inmate interviewed in the Madre Pelletier Women's Penitentiary. This analysis also has the objective of questioning the way the prisons function, according to Michel Foucault studies. The women decide to be silent when facing the possibility of coercion from the laws of the institution, resisting to its domination and creating a different way of the prison to work from the interior of the galleries. This leads to Pêcheux's statement that there is no domination without resistance. Discourse Analysis allows us to achieve the understanding of these relations through the linguistic-prosodical materialization of the ideology and, also, of the ways the dominated discourse resists.
\end{abstract}

Keywords: resistance; prison; silence.

\footnotetext{
${ }^{1}$ Doutora em Letras pela UFRGS. Professora no Programa de Pós-Graduação em Letras da UFPEL. http://lattes.cnpq.br/2001548222755825.
} 


\section{Introdução}

O sistema carcerário brasileiro abriga milhares de mulheres e de homens cujas vidas passam a ser reguladas por um aparelho que não cumpre, minimamente, com exigências dos Direitos Humanos. Celas superlotadas, sem circulação de ar e sem luz natural, ausência de materiais de higiene pessoal, baixa qualidade nos alimentos fornecidos, falta de atendimento médico, dentre outros problemas mais sérios, são facilmente verificados nos presídios nacionais. No Rio Grande do Sul, são mais de 30 mil $^{2}$ mulheres e homens encarcerados em estabelecimentos penais não adequados para servir de residência para seres humanos. É possível afirmar que a repressão e a desvalorização humana, observadas no funcionamento dos presídios, operam diretamente na forma como os sujeitos se identificam com os saberes oriundos da superestrutura jurídico-político-ideológica.

Nesse sentido, o interior das prisões é marcado por dois tipos de regulação: uma regulação "que vem de fora", efeito das determinações jurídico-político-ideológicas, e uma regulação interna, a qual ocorre no interior das galerias prisionais. Compreendemos que tal processo de dupla determinação deve ser investigado e, em função disso, é chamada a Análise do Discurso na tradição de Michel Pêcheux (doravante AD). O presente trabalho, então, tem o objetivo de refletir sobre a existência da resistência no interior da instituição penal a partir da fala ${ }^{3}$ de uma apenada da Penitenciária Feminina Madre Pelletier quando aborda o funcionamento da prisão. A mulher entrevistada cumpria pena há sete anos e ainda deveria ficar mais sete anos no interior da Penitenciária. Esta instituição penal, localizada na zona urbana da cidade de Porto Alegre-RS, tem capacidade para abrigar 239 presas; no entanto, no momento da realização da entrevista, eram 271 apenadas que viviam na instituição.

Com isso, justificamos a importância do trabalho em função da necessidade de se refletir sobre o modo de funcionamento das prisões, seguindo elaboração de Michel Foucault, e, também, sua teorização sobre os corpos dóceis, pois percebe-se que, no interior da instituição prisional, local onde os sujeitos são transformados em corpos analisáveis e manipuláveis, há espaço para a resistência. A reflexão contará, portanto, com uma teorização acerca da resistência e dos processos de subjetivação conforme Pêcheux (2009), bem como versará sobre a prisão na compreensão de Foucault (2003, 2005). Após a apresentação do recorte da fala da apenada, será feita uma análise sobre a relação entre resistência e silêncio, de acordo com a perspectiva de Dinouart (2001).

\section{Fundamentação teórica}

Um dos pontos tocados por Michel Foucault em sua vasta reflexão concerne ao modo de funcionamento das prisões. $\mathrm{O}$ autor aborda a função de normatização dos indivíduos a partir de instituições de arquitetura panóptica, tal como a instituição penal.

\footnotetext{
${ }^{2}$ Em 15 de agosto de 2016, o número de mulheres presas no estado do Rio Grande do Sul era de 1.953, ao passo que 32.451 homens se encontravam em estado de privação de liberdade. Os dados foram retirados do site da SUSEPE. Disponível em http://www.susepe.rs.gov.br/capa.php. Acesso em 15 de ago. de 2016.

${ }^{3}$ Optou-se pela designação "fala" em função de ser feita referência ao corpus empírico do presente estudo, o qual se constitui por texto oral gravado e transcrito, ou seja, diz respeito à voz da apenada entrevistada.
} 
Essas instituições, também chamadas por Foucault de instituições de sequestro, visam a controlar o tempo dos indivíduos. Duas de suas funções podem ser citadas, a saber, a extração da totalidade do tempo e o controle dos corpos. Isso significa que, para o seu funcionamento, deve existir uma disciplina geral da existência.

O autor elenca quatro razões do controle da existência dos indivíduos. A primeira concerne a controlar, formar e valorizar o corpo do indivíduo segundo determinado sistema: o corpo "deve ser formado, reformado, corrigido, o que deve adquirir aptidões, receber um certo número de qualidades, qualificar-se como corpo capaz de trabalhar" (FOUCAULT, 2003, p. 119). A segunda razão diz respeito à transformação dos corpos dos homens em força de trabalho, correspondente à função de transformação do tempo em tempo de trabalho. Um terceiro ponto elencado por Foucault faz menção à criação de um novo tipo de poder, polimorfo e polivalente; econômico, judiciário e político; o qual envolve um julgamento no tribunal e uma observação por um micro-tribunal, constituído pelos guardiões e pelo diretor da prisão. A quarta razão do controle da existência dos indivíduos seria relacionada a um poder epistemológico, objetivando "extrair dos indivíduos um saber e extrair um saber sobre estes indivíduos submetidos ao olhar e já controlados por esses diferentes poderes" (FOUCAULT, 2003, p. 121). A partir disso, surgiria um outro saber: um saber sobre os indivíduos e suas classificações, psiquiátrico, psicológico, criminológico.

A prisão, enquanto instituição de sequestro, e, portanto, enquanto promotora da transformação da vida dos homens em força produtiva, possui uma função exemplar, e não econômica, penal ou corretiva. A seguinte afirmação de Foucault (2003) resume a lógica de funcionamento da prisão.

Que o tempo da vida se torne tempo de trabalho, que o tempo de trabalho se torne força de trabalho, que a força de trabalho se torne força produtiva; tudo isto é possível pelo jogo de uma série de instituições que esquematicamente, globalmente, as define como instituições de sequestro. Parece-me que, quando interrogamos de perto estas instituições de sequestro encontramos sempre, qualquer que seja seu ponto de inserção, seu ponto de aplicação particular, um tipo de invólucro geral, um grande mecanismo de transformação: como fazer do tempo e do corpo dos homens, da vida dos homens, algo que seja força produtiva. É este conjunto de mecanismo que é assegurado pelo sequestro. (p. 122)

No sistema capitalista que se iniciou no século XIX, o homem é fixado ao trabalho a partir de técnicas através das quais o corpo e o tempo se tornam força de trabalho e tempo de trabalho, respectivamente, transformados em sobre-lucro. O sobre-lucro se origina de um sub-poder, ou seja, de um poder político que fixa os homens a um aparelho de produção, um conjunto de pequenos poderes, situados em um nível mais baixo.

Foucault também insere em sua reflexão o conceito de corpo dócil, o qual reflete a união de um corpo manipulável a um corpo analisável. Esse corpo dócil pode ser submetido, utilizado, transformado e aperfeiçoado (FOUCAULT, 2005, p. 118), e as técnicas que instauram essas ações de controle minucioso dos corpos possuem uma escala infinitesimal através de uma coerção ininterrupta. O método responsável por esse controle são as disciplinas, compreendidas como formas gerais de dominação, como "uma 
anatomia política do detalhe" (op. cit., p. 120), "uma tecnologia específica de poder" (op. cit., p. 161), "uma "anatomia" do poder" (op. cit., p. 177), as quais são parte do biopoder.

Trata-se, portanto, de uma modalidade de exercício de poder, não identificável diretamente com uma instituição determinada, que abriga instrumentos, técnicas, procedimentos, níveis de aplicação, alvos, assegurando uma "distribuição infinitesimal das relações de poder" (op. cit., p. 177). Consoante Passos (2008), ao invés de um poder de tipo repressivo há, nas sociedades modernas, um poder atuante, de tipo disciplinar, o qual "opera por meio de estratégias, táticas e técnicas sutis de adestramento: uma conformação física, política e moral dos corpos” (p. 12). O poder disciplinar, em oposição ao poder soberano, opera através da norma, a fim de disciplinar os corpos.

Apesar de o pensamento de Foucault ser extremamente importante para a reflexão sobre o papel das prisões na formação social, é interessante observar a relação entre os pontos ressaltados pelo autor e a forma como a Penitenciária Feminina Madre Pelletier funciona. Em função de existir a possibilidade de resistência no interior da instituição penal, conforme será observado a seguir, é necessário abordar, ainda que de forma breve, a teorização de Michel Pêcheux sobre a resistência. Nesse sentido, primeiramente, traremos uma afirmação de Pêcheux presente no Anexo III da obra Semântica e discurso: uma crítica à afirmação do óbvio.

Foucault traz uma contribuição importante para as lutas revolucionárias de nosso tempo, mas, simultaneamente, ele a torna obscura, ficando inapreensíveis os pontos de resistência e as bases da revolta de classe. Farei a hipótese de que esse obscurecimento se dá pela impossibilidade, do ponto de vista estritamente foucaultiano, de operar uma distinção coerente e consequente entre os processos de assujeitamento material dos indivíduos humanos e os procedimentos de domesticação animal. Esse biologismo larvado, que ele partilha, em todo o desconhecimento de causa, com diversas correntes do funcionalismo tecnocrático, torna, consequentemente, a revolta totalmente impensável, pois, assim como não poderia haver "revolução dos bichos", também não poderia haver extorsão de sobre-trabalho ou de linguagem no que se convencionou chamar reino animal. (PÊCHEUX, 2009, p. 279)

Como pode ser observado, Pêcheux formula uma crítica ao pensamento foucaultiano no que tange à possibilidade de resistência, visto que Foucault atribui à dominação um caráter de domesticação animal ao se falar sobre os corpos dóceis e sobre os procedimentos de normatização dos indivíduos. A revolta, portanto, não pode ser cogitada por indivíduos comparados a quaisquer seres do reino animal. Não é isso o que pensa Pêcheux, o que nos traz a possibilidade de um deslocamento na reflexão sobre o funcionamento das prisões.

É a partir desse ponto que retomamos a divisão instaurada por Pêcheux na constituição da subjetividade, a qual diz respeito ao inconsciente e à ideologia. Nesse sentido, é importante trazer uma retomada feita por Baldini (2009) sobre a dependência existente entre ideologia e produção de sentido. O autor enfatiza dois pontos importantes: (i) o princípio de Althusser de que "a ideologia se dá através de práticas (ou ainda, da repetição de rituais materiais), não podendo ser entendida como conjunto de ideias" (p. 1); e, também, (ii) uma consideração dependente da primeira, a qual diz respeito ao fato 
de que, para Pêcheux, "não há sentido que não seja ideológico, isto é, que a própria constituição do sentido (e do sujeito do discurso) se dá pela via da ideologia” (p. 1).

Através das práticas reproduzidas na formação social, as quais materializam a ideologia, é que se estabelece o sentido, ou melhor, o discurso. Nesse processo, podem ocorrer três modalidades ${ }^{4}$ de subjetivação, ou seja, três formas possíveis de relação do sujeito com a ideologia, as quais dependem da existência de formações discursivas, conforme proposto por Pêcheux (2009). É a partir dos saberes presentes nas formações discursivas que ocorre o processo de subjetivação, ou, melhor dizendo, é da identificação do sujeito com os saberes das formações discursivas que o sujeito se subjetiva. Essa relação entre sujeito e saberes se dá através da identificação, da contraidentificação e da desidentificação, as quais serão descritas, de forma breve, como segue.

$\mathrm{Na}$ identificação, compreendida como a primeira modalidade de subjetivação, o sujeito se identifica com os saberes da formação discursiva dominante, sendo determinado por ela, ocorrendo uma superposição entre o sujeito da enunciação e o sujeito universal (PÊCHEUX, 2009). Segundo Beck \& Esteves (2012), "uma superposição, um recobrimento, segundo Pêcheux, permitiria uma identificação plena do sujeito (autômato), que funcionaria sozinho, sem policiamento contínuo e sem qualquer dúvida sobre a posição assumida no âmago de uma formação ideológica" (p. 141). A contraidentificação acontece quando o sujeito passa a questionar esses saberes, lutando contra as evidências fornecidas pela ideologia, possibilitando com que o sujeito da enunciação "se volte" contra o sujeito universal (PÊCHEUX, 2009). Já a terceira modalidade, compreendida como desidentificação, ocorre quando da identificação do sujeito com outra formação discursiva, desvinculando-se daquela que, originalmente, fornecia-lhe os sentidos. Desse modo, o sujeito do discurso passa a se identificar com a forma-sujeito de outra formação discursiva.

A partir dessas formas de funcionamento subjetivo, podemos pensar, então, como ocorre a rachadura no processo de interpelação ideológica, momento em que o sujeito questiona e luta contra aquilo que o determina. Na primeira modalidade de subjetivação, questionada pelo próprio Pêcheux ${ }^{5}$, não haveria a possibilidade de o ritual falhar (ou seja, a contraidentificação e a desidentificação seriam da ordem do impossível), em função de o sujeito ser um ego pleno, sem lugar para o inconsciente. Contudo, com a retificação operada pelo próprio autor, a resistência é, sim, possível.

Ainda sobre a falha, segundo Baldini \& Zoppi-Fontana (2013), pensar diferentemente a relação das ideologias dominantes e dominadas coloca em termos novos a questão das práticas de resistência e de revolta, consideradas como "falha, desmaio ou rachadura" nos rituais de interpelação ideológica. É por isso que se faz necessário trazer aqui a proposta de Beck \& Esteves (2012) sobre as modalidades de subjetivação. Os autores colocam que

\footnotetext{
${ }^{4}$ Apesar de o termo "modalidade" parecer remeter a "categorias" de funcionamento subjetivo, o que poderia reduzir a complexidade teórica da proposta de Michel Pêcheux sobre as diferentes formas como o sujeito se subjetiva, optou-se, no presente texto, pela manutenção da designação proposta por Pêcheux (2009), conforme pode ser observado na seguinte citação: "comecemos por constatar que esse desdobramento [entre "sujeito da enunciação" e "sujeito universal"] pode assumir diferentes modalidades, duas das quais são "evidentes"” (p. 199; grifo nosso).

${ }^{5}$ No Anexo III da obra Semântica e Discurso: Uma crítica à afirmação do óbvio, publicado em 1978, Pêcheux questiona a plena identificação do sujeito com a ideologia.
} 
No mesmo texto de retificação, Pêcheux [1978] discorre sobre o processo de resistência-revolta-revolução. Não estaria cada um destes "momentos" do processo associado às três modalidades respectivamente? Ou seja, o bom sujeito mantém-se identificado ao Sujeito, mas também resiste a Ele; o mau sujeito se contraidentifica ao Sujeito e, por isso mesmo se revolta contra Ele; e o feio sujeito se desidentificaria e, por conseguinte, teria condições de subverter suas coordenadas ideológicas, de revolucionar as relações de forças. (p. 152)

Nesse sentido, a resistência é constitutiva do processo de identificação. O mesmo aconteceria com a contraidentificação e com a revolta, na segunda modalidade, e com a desidentificação e a revolução, na terceira modalidade. A resistência, a revolta e a revolução atravessam, portanto, a forma como o sujeito se subjetiva.

Assim, chegamos ao ponto principal da presente reflexão: seria possível a resistência acontecer através do silêncio? A mesma pergunta é feita por Beck (2013): "Uma vez interpelado o indivíduo em sujeito, há possibilidade de recusar a injunção ao dizer (idem, p.264)?” (p. 74). Trazemos, então, o pensamento do Abade Dinouart, o qual, em 1771, escreve um livro de retórica cristão ${ }^{6}$. Dinouart, segundo Beck (2013), diz que "o silêncio é dotado de potência para afetar os outros sujeitos, afetar a relação (de forças) entre os sujeitos de modo a acarretar efeitos políticos" (p.76). Courtine \& Haroche (2001), os quais escreveram a apresentação da obra do Abade Dinouart, salientam que o autor não fala sobre uma arte de fazer silêncio, mas, sim, "de uma arte de fazer alguma coisa ao outro pelo silêncio" (p.VIIII), daí decorrem os efeitos políticos do silenciar, conforme comentado por Beck (2013).

Tem-se aqui, portanto, a importância de se abordar a relação entre silêncio e sentido ao se trazer à tona os efeitos políticos do silêncio. Beck (2013) aprofunda mais essa questão quando resgata Althusser para falar sobre a reprodução das relações de produção:

Se desde Althusser entendemos a ideologia dominante como prática que assegura a reprodução das relações de dominação-exploraçãosegregação por meio de sua repetição incessante, ainda que sujeita a falhas, então não é possível pensar na suspensão, ainda que momentânea, de sua repetição como uma forma de desobediência civil? (p. 74)

A suspensão do processo de reprodução das relações de produção, através do silêncio, poderia trazer, então, uma desobediência civil. Parece que é isso o que acontece no caso das apenadas da Penitenciária Feminina Madre Pelletier, como poderá ser visto em seguida. Importante referir que o processo de silenciamento como forma de resistência não se dá, simplesmente, como um "fechar a boca", mas, como diz Dinouart (2001), é necessário saber governar a língua:

\footnotetext{
${ }^{6}$ Apesar de reconhecermos as importantes contribuições de Eni Orlandi sobre a questão do silêncio nos estudos discursivos, não faremos referência à obra da autora (ORLANDI, 2007) em função de a forma como trabalhamos o silêncio no presente texto se aproximar do pensamento de Dinouart (2001). Conforme pode ser observado ao longo deste trabalho, o silêncio não será evocado, portanto, como silêncio fundante, tampouco como política de censura.
} 
Suponho aqui que, para bem calar, não basta fechar a boca e não falar: não haveria nisso nenhuma diferença entre o homem e os animais; estes são naturalmente mudos; mas é preciso saber governar a língua, considerar os momentos convenientes para retê-la ou dar-lhe uma liberdade moderada; seguir as regras prescritas pela prudência nesta matéria; distinguir, nos acontecimentos da vida, as ocasiões em que o silêncio deve ser inviolável; ter uma firmeza inflexível quando se trata de observar, incessantemente, tudo o que se considerou conveniente para bem calar". (p. 10)

Encerrando a presente seção, trago mais uma ponderação feita por Dinouart (2001). O abade menciona que é somente no silêncio que o ser humano é plenamente dono de si mesmo, pois, fora do silêncio, pode cair no excesso e deixar de pertencer a si mesmo e pertencer mais aos outros. É nesse sentido que a análise das falas das apenadas pode trazer elementos que não digam respeito somente à possibilidade de resistência no interior da prisão, mas a algo mais próprio da subjetividade como lugar da falha e do ousar pensar por si mesmo, como diz Pêcheux no texto de 1978 presente na obra Semântica e discurso.

\section{Análise e Discussão}

A apenada entrevistada para o trabalho, conforme foi mencionado anteriormente, estava em regime de privação de liberdade há sete anos e ainda deveria ficar mais sete anos na cadeia ${ }^{7}$. A pena dela era, originalmente, de 54 anos de prisão. Por questões éticas, não foi possível dizer o seu nome e, em função disso, ele foi substituído por uma cor: Branca. Branca era mãe de três filhos e os motivos para a sua prisão envolveram assalto a banco e troca de tiros com a polícia. Os recortes da fala da apenada estão organizados em duas sequências discursivas (SD), as quais dizem respeito à relação entre resistência e silêncio.

(SD1) geralmente não são levada pra... pra polícia... não são levada pras agenti as briga... briga di galeria é resolvida dentro da galeria... não são levadas pra elas a não sê que a pessoa... se atire nos braço das agenti e di/peça socorro... sinão não... é tudo resolvido internamenti ali mesmo... sempre foi... sempre foi assim (risos)

(SD2) entre as presas... ou discussão ou... alguém vem apaziguá... ou elas brigam mesmo... e pronto... termina ali... a não sê qui né... que uma mais escandalosa desça correndo a escada e chame a polícia né... mas geralmente é resolvido entre a genti mesmo... internamente dentro da galeria... é assim... o sistema todo é assim... né... a polícia manda... mas a polícia manda... paralelo... com as presas... eles mandam... mas a genti... as presa também mandam... é... embora eles não... eles não assumam isso né... eles sabem que tem... toda cadeia tem todas as cadeia têm... tem o controle pra fora do portão ih o controle pra dentro do

\footnotetext{
${ }^{7}$ A entrevista foi realizada em abril de 2013 no interior da Penitenciária Feminina Madre Pelletier. Foram utilizados dois gravadores digitais, sendo que, após a gravação, foi feita a transcrição da fala da apenada. A entrevista era semiestruturada, ou seja, as perguntas feitas para a apenada não obedeciam a uma ordem fixa e pré-determinada.
} 
portão né... e as presas têm que íh no ritmo... que a cadeia é... pra corrê tudo bem... por exemplo eu não me envolvo com nada... pra mim tá tudo bem... agora chega uma uma que já não vai aceitá é ai as regra da cadeia toda cadeia tem regra e cada galeria tem a sua regra também... então... aí já fica difícil né... mas tem um controle paralelo sim... meio das presa e meio deles embora eles nunca vão assumi isso né eles acham que têm o controle total da cadeia isso é mentira.

Na SD1, chamamos a atenção para o seguinte recorte: "briga di galeria é resolvida dentro da galeria". Já na SD2, podemos lançar luz sobre os recortes a seguir: "geralmente é resolvido entre a genti mesmo... internamente dentro da galeria... é assim... o sistema todo é assim"; "a polícia manda... mas a polícia manda... paralelo... com as presas... eles mandam... mas a genti... as presa também manda... é... embora eles não... eles não assumam isso né"; "tem o controle pra fora do portão ih o controle pra dentro do portão né"; e "mas tem um controle paralelo sim... meio das presa e meio deles embora eles nunca vão assumi isso né eles acham que têm o controle total da cadeia isso é mentira".

Os recortes feitos na SD1 e na SD2 trazem à tona a convivência de saberes antagônicos no modo de funcionamento da instituição penal, compreendida como Aparelho Repressivo de Estado. Por um lado, há a lei do Estado operando na forma como a Penitenciária se organiza, a qual tem o dever de punir quaisquer apenadas que descumpram as regras da instituição penal; por outro lado, há a lei do interior das galerias, ou seja, há uma lei criada pelas próprias apenadas, sobre a qual o Aparelho Repressivo não tem interferência, e da qual o ARE não tem conhecimento. Sendo assim, há o descumprimento da lei do ARE no interior das galerias sem que a polícia tome conhecimento desse fato: há uma lei que opera fora da lei da prisão, o que revela o funcionamento da contradição. Há uma relação de cumplicidade entre as apenadas no que diz respeito à forma como elas devem se comportar no interior das galerias. A fim de evitar a punição da polícia, as apenadas compactuam em se manter em silêncio no caso de brigas internas. Esse silêncio é tido como uma forma de resistência, ou seja, as apenadas se identificam com saberes não condizentes com aqueles da forma-sujeito de Direito. Tais são os efeitos políticos do silêncio no modo de funcionamento da Penitenciária Feminina Madre Pelletier.

Consideramos, então, que há espaço para a resistência na prisão, a qual se manifesta através do silêncio, ou seja, as apenadas organizam, no interior das galerias, modos de se manter na prisão enquanto desvinculadas das suas leis, estabelecendo uma lei própria, avessa à determinação institucional. Elas se calam frente à possibilidade de coerção das leis da Penitenciária, promovendo a resistência à dominação da instituição penal e instaurando outro modo de funcionamento da prisão a partir do interior das galerias, podendo ser retomado o enunciado pêcheuxtiano de que não há dominação sem resistência. Conforme exposto pela apenada entrevistada, o silêncio como regulador interno das galerias permite que as apenadas não se exponham à coerção do Aparelho Repressivo de Estado, o que caminha no sentido de uma revolta contra os saberes da formação discursiva que regula o funcionamento da instituição penal, a qual não está avessa à operação da ideologia. Apesar de a prisão ser uma instituição vinculada ao Aparelho Repressivo de Estado, sendo autorizada a utilizar da coerção física para fazer valer a lei, não significa que ela esteja desvinculada da ideologia, posto que faz parte da superestrutura jurídico-político-ideológica. 
Retomando Baldini (2009), não há sentido que não seja ideológico e a ideologia ocorre através de práticas. Na fala de Branca, podemos compreender como ocorre a relação entre as apenadas e a polícia no interior da instituição penal. Segundo Branca, briga de galeria fica dentro de galeria, o sistema todo funciona assim, o controle da prisão é feito de forma paralela, a polícia não sabe que as presas também mandam. É, portanto, silenciando que as apenadas conseguem resistir às coerções do Aparelho Repressivo de Estado.

O silêncio opera como uma resistência na medida em que o que acontece no interior das galerias não é determinado pela polícia: é uma forma de desobediência civil. As apenadas só podem mandar se a polícia não ficar sabendo daquilo que acontece internamente. Polícia e presas possuem a mesma autoridade, o que garante a existência de um conflito político no interior das galerias, o qual só é reconhecido pelas próprias apenadas. Essas afirmações são possíveis de serem feitas com base nos sentidos estabelecidos a partir da fala da apenada. Na sua interpretação, a polícia não sabe da organização interna do presídio, promovida pelas próprias apenadas. Podemos questionar se a polícia não estaria fazendo funcionar a ideologia de forma cínica, isto é, a polícia saberia desse regulamento interno da prisão, mas se manteria afastada das decisões tomadas pelas próprias apenadas.

As palavras do Abade Dinouart parecem ser pertinentes para a situação acima relatada: ele menciona que o silêncio afeta a relação de forças entre sujeitos acarretando efeitos políticos. Caso as apenadas não silenciassem, o controle da polícia seria total no interior da penitenciária, e traria efeitos punitivos (poderiam ir para o castigo, por exemplo).

Contudo, é importante lembrar que existe uma falha no processo relatado por Branca: ela diz que: "[as brigas] não são levadas pra elas a não sê qui a pessoa... se atire nos braço das agenti e di/peça socorro" (SD1); "a não sê qui né... uma mais escandalosa desça correndo a escada e chame a polícia né”. Desse modo, é sempre possível que uma apenada que fique com medo, que não se sinta segura no interior das galerias, busque o apoio das agentes penitenciárias para resolver o conflito interno. É quando ocorre a falha no ritual de silenciamento compactuado entre as apenadas: a apenada, ao chamar a polícia, estaria identificada com a lei do Aparelho Repressivo, ao invés de reproduzir os sentidos vinculados à forma de funcionamento interno da prisão.

\section{Considerações finais}

O dispositivo teórico-analítico da Análise do Discurso permite que sejam observadas materialidades que apontem para o funcionamento da ideologia no seio de uma determinada formação social. Com a análise aqui empreendida, foi possível compreender como a resistência se instala em uma Penitenciária, local historicamente compreendido como excludente. Desse modo, compreendemos como opera a relação entre os sujeitos em situação de privação de liberdade com a superestrutura jurídicopolítico-ideológica, na figura do Aparelho Repressivo de Estado (a polícia). Nessa relação, há, sim, possibilidade de resistência, e ela pode ocorrer a partir da arte de calar, ou, melhor dizendo, do silenciar. 
Sendo assim, a citação de Baldini e Zoppi-Fontana (2013) sobre os procedimentos analíticos da Análise do Discurso é trazida para o trabalho, na qual os autores mencionam que:

A variedade temática e os diversos recortes em termos de objetos de pesquisa contribuem para mostrar a intensa vitalidade e originalidade desta corrente de estudos da linguagem e sua pertinência e potência para a análise da relação da linguagem com os processos históricos de constituição do sentido e do sujeito. Também nos apontam para o compromisso fundante desta abordagem discursiva, que considera necessária e desejável a conjunção da teoria e da prática política, aliando o rigor da descrição analítica ao vigor de uma tomada de posição explícita pela transformação política da sociedade. (p. 5)

É por isso que a Análise do Discurso deve ser entendida como um dispositivo que visa à intervenção política, à militância transformadora, no sentido de instaurar novos processos de significação desvinculados da ideologia dominante na formação social capitalista contemporânea.

\section{Referências bibliográficas}

BALDINI, L.J.S. Cinismo, discurso e ideologia. Em: Anais do IV Seminário de Estudos em Análise do Discurso, 4, Porto Alegre, RS, UFRGS, 2009. Disponível em http://anaisdosead.com.br/4SEAD/SIMPOSIOS/LauroJoseSiqueiraBaldini.pdf. Acesso em 5 de abril de 2016.

; ZOPPI-FONTANA, Mónica Graciela. A Análise do Discurso no Brasil. Décalages, vol. $\quad 1, \quad$ n. 4 , 2013. $\quad$ Disponível em http://scholar.oxy.edu/cgi/viewcontent.cgi?article=1082\&context=decalages. Acesso em 20 de abril de 2016.

BECK, Maurício. Apraxia e silenciar: formas de resistência-revolta por meio de uma subtração subjetiva. Conexão Letras, v. 8, 71-82, 2013. Disponível em http://seer.ufrgs.br/index.php/conexaoletras/article/view/55180/33559. Acesso em $10 \mathrm{de}$ outubro de 2015.

; ESTEVES, P.M. O sujeito e seus modos - identificação, contraidentificação, desidentificação e superidentificação. Leitura, v. 2, 135-162, 2012. Disponível em http://www.seer.ufal.br/index.php/revistaleitura/article/view/1152/787. Acesso em 4 de outubro de 2015.

COURTINE, J-J.; HAROCHE, C. Apresentação. Em: DINOUART, J-A.T. A arte de calar. Trad. Bras. São Paulo: Martins Fontes, 2001.

DINOUART, J-A.T. A arte de calar. Trad. Bras. São Paulo: Martins Fontes, 2001.

FOUCAULT, M. Vigiar e punir: nascimento da prisão. Trad. Bras. 30ª ed. Petrópolis: Vozes, 2005. 
A verdade e as formas jurídicas. Trad. Bras. 3ª ed. Rio de Janeiro: NAU, 2003.

ORLANDI, Eni Puccinelli. As formas do silêncio: no movimento dos sentidos. $6^{\mathrm{a}}$. ed. Campinas: Editora da UNICAMP, 2007.

PASSOS, I.F. Apresentação. Situando a analítica do poder em Michel Foucault. Em: Poder, normalização e violência: incursões foucaultianas para a atualidade. Belo Horizonte: Autêntica, 2008.

PÊCHEUX, Michel. Semântica e discurso: uma crítica à afirmação do óbvio. Trad. Bras. 4 a . ed. Campinas: Editora da UNICAMP, 2009.

Artigo recebido em: outubro de 2016.

Aprovado e revisado em: dezembro de 2016.

Publicado em: abril de 2017.

\section{Para citar este texto:}

VINHAS, Luciana Iost. Uma análise discursiva do silêncio na prisão. Entremeios [Revista de Estudos do Discurso, on-line], Seção Estudos, Programa de Pós-Graduação em Ciências da Linguagem (PPGCL), Universidade do Vale do Sapucaí (UNIVÁS), Pouso Alegre (MG), vol. 14, p. 51-61, jan. - jun. 2017.

DOI: http://dx.doi.org/10.20337/ISSN2179-3514revistaENTREMEIOSvol14pagina51a61 